\title{
Reproductive hormones in seminal plasma; it's effect on semen quality
}

\author{
*S. Wijeratna', H. R. Seneviratne', W. D. Ratnasooriya ${ }^{2}$ \\ The Ceylon Journal of Medical Science 2005; 48: 53-60
}

\section{Abstract}

The aim of this study was to investigate the effect of reproductive hormones in seminal plasma on the quality of the spermatozoa in men seeking infertility treatment. Of the 383 volunteers recruited, 123 had normal sperm parameters and 260 had either a single or a combination of sperm abnormalities as per WHO criteria. Follicle Stimulating Hormone (FSH), Luteinizing Hormone (LH) Prolactin (PRL), Testosterone (T) and Estradiol (E2) levels in serum and semen of these men were determined using an immunometric chemiluminisance assay. Of the serum hormones, FSH, LH were significantly higher ( $\mathrm{p}<0.001$ for both) and T levels were significantly lower $(p<0.01)$ in men with abnormal semen compared with the men with normal semen parameters. Serum PRL and E2 in both the groups did not show any significant difference. With regard to semen hormones FSH, LH and T levels in men with normal and abnormal semen did not show any significant difference. In contrast, men with abnormal semen had significantly higher levels of semen PRL ( $p<0.001)$ and E2 $(\mathrm{p}<0.01)$ compared with those in men with normal semen. Moreover, semen PRL showed a significant negative correlation with sperm motility $(\mathrm{r}=-0.398 ; \mathrm{p}<0.001)$, morphology $(r=-0.32 ; p<0.01)$ and viability $(\mathrm{r}=-0.328 ; \mathrm{p}<0.01)$. Further, a positive correlation between PRL and semen volume was observed in both semen normal and
\end{abstract}

abnormal groups $(r=0.21 ; p<0.05)$. Semen $\mathrm{E} 2$ in the abnormal group also showed a significant negative relationship with sperm motility $(r=-0.305 ; p<0.01)$. In conclusion, in men with abnormal semen parameters both PRL and E2 in seminal plasma have a negative impact on sperm motility. It was also evident that semen PRL has a negative impact on sperm morphology and viability.

\section{Introduction}

The biological process of reproduction is influenced by multiple factors. The male factor plays a role in over $50 \%$ of the infertile couples (1). Male infertility may be due to deficient sperm production, impaired transport or defective sperm parameters which include abnormalities in the sperm count, motility, morphology and viability (2). Normality or abnormality of semen is regarded as an indicator of the function of the male reproductive system and semen quality is of pivotal importance in predicting male fertility.

Isolated seminal plasma abnormalities include abnormalities in the physical and biochemical composition as well as the presence of pathogens. The significance of these abnormalities in the etiology of infertility is unknown (3). As seminal plasma is the immediate environment of spermatozoa, the substances in the seminal

1. Department of Obstetrics and Gynaecology, Faculty of Medicine, Colombo.

2. Department of Zoology, Faculty of Science, University of Colombo, Sri Lanka.

* Author for correspondence 
plasma could be expected to have a profound effect on the quality of the sperm. Although several biological functions are attributed to seminal plasma there is no agreement among the researchers in andrology with regard to these functions. The significance of the seminal plasma abnormalities in the etiology of infertility is unknown (3). However, Burkman (1995) has stated that the patterns of sperm motility and function are influenced by the composition of seminal plasma (4).

Endocrine factors are likely to affect the sperm quality via two mechanisms: i.e. by affecting spermatogenesis or by directly affecting sperm functions via receptors, thereby the sperm quality. Malproduction and malfunction of hormones are also known causes of pathological changes in the male reproductive function and hence of male infertility. Since spermatozoa never come in contact with blood, it is the seminal hormones that act on sperm receptors. Several researchers $(5,6,7,8)$ have demonstrated presence of a range of steroid hormones, their precursors and metabolites together with their regulatory pituitary hormones in seminal plasma. As measurable quantities of hormones are found in the seminal plasma in which the sperm live, these hormones are likely to affect the quality of sperm activity. However studies on effects of reproductive hormones in serum and semen on overall semen quality are scarce globally and none have been conducted in Sri Lanka. The available data are focused mainly on the relationship of seminal hormones to sperm concentration and/or motility and the results are conflicting. Moreover, to our knowledge, no study has been carried out to find any relationship between semen hormones and sperm viability. There appears to be no agreement with regard to the levels and effects of hormones in semen on human sperm quality. As such, this study was designed to assess the reproductive hormone levels in serum and seminal plasma and to determine the effect of semen hormones on sperm count motility, morphology and viability in mer with normal and abnormal sperm parameters.

\section{Material and Methods}

This prospective observational study was conducted from January 2000 to December 2002 at the Reproductive Biology Laboratory of the Department of Obstetrics and Gynaecology, Faculty of Medicine University of Colombo, Sri Lanka. Ethica clearance to carry out this study was obtained from the Ethical Review Committee of the Faculty of Medicine, University of Colombo.

Male partners of the couples attending the infertility clinic of the Department of Obstetrics and Gynaecology were invited to participate in the study. A total of 383 volunteers among the 1110 male partners who sought treatment during the study period were recruited. The selection criteria used for recruitment of patients were those of age between 20 to 45 years, with no endocrinological therapy for at least months before the recruitment, with no endocrinological disorder, significant systemic illnesses or infectious diseases affecting male fertility.

Semen and blood samples were collected from all the men $(n=383)$ who volunteered to participate in the study. Men were requested to produce semen samples according to WHO guidelines (9). A blood sample $(5 \mathrm{ml})$ was collected prior to semen collection. Seminal Fluid Analysis (SFA) was performed as per WHO criteria. If one or more semen parameters were abnormal in a sample it was repeated to confirm the abnormality. Using WHO reference values for semen, the study sample was divided into 
two groups i.e. men with normal and those with abnormal semen parameters.

Serum and the seminal plasma were separated by centrifugation $(1500 \mathrm{~g}$ for 10 min.) at room temperature $\left(28-30^{\circ} \mathrm{C}\right)$. Both serum and seminal plasma samples were stored frozen at $-20^{\circ} \mathrm{C}$ until the hormone assays were performed.

Hormone levels in serum and seminal plasma were assayed simultaneously, by immunometric chemiluminisance assay using the Immulite analyzer (Diagnostic Product Cooperation, CA, USA). All hormone assays carried out for the study were validated and inter- and intra-assay coefficients of variance (CV) calculated. The inter- and intra-assay CV values were $4.9 \%$ and $5.8 \%$ for $\mathrm{FSH}, 3.5 \%$ and $5.2 \%$ for $\mathrm{LH}$, $4.9 \%$ and $4.7 \%$ for PRL, $3.9 \%$ and $4.0 \%$ for $\mathrm{E} 2,6.7 \%$ and $7.1 \%$ for $\mathrm{T}$, respectively.

Viscous seminal plasma samples were syringed through $22 \mathrm{G}$ needles in order to reduce the viscosity and homogenize them for accurate pippeting before analysis. The samples with serum PRL levels above the normal value $(420 \mathrm{mIU} / \mathrm{L})$ were repeated after obtaining a blood sample through a cannula inserted 30 minutes prior to collection.

Statistical analysis was carried out using the SPSS for Windows Release 10.0.5, Minitab Version 13 and Microsoft Excel 97. p values of $<0.05 \%$ were considered as statistically significant. The results are presented as mean \pm SEM. Correlations were assessed using Pearson's correlation coefficient.

\section{Results}

Semen analysis was interpreted as normal or abnormal according to WHO criteria. Of the 383 men, 123 had normal sperm parameters and 260 had either single or a combination of sperm abnormalities. The mean values of sperm variables are shown in Table 1. The mean serum and semen hormone levels in men with normal and abnormal semen are depicted in Table 2. Serum FSH and LH levels were significantly higher and $\mathrm{T}$ levels were significantly lower in the SFA abnormal group than the normal group. There was no significant difference in the mean PRL and E2 levels in the serum samples of individuals with normal or abnormal semen parameters.

In contrast, semen FSH, LH and T levels were lower and semen E2 and PRL levels were significantly higher than those of serum in both normal and abnormal groups. Moreover, semen PRL levels and semen E2 were significantly higher in the SFA abnormal group than those of SFA normal group.

The correlation between PRL levels in serum and semen with sperm parameters are shown in Table 3 and 4 . Of the five hormones evaluated, serum and semen hormones in the SFA normal group did not show any significant correlation with sperm parameters except semen PRL, which showed a significant positive correlation with the semen volume (Table 3 ).

In the SFA abnormal group, serum PRL, E2 and $T$ did not show any significant relationship with any of the sperm parameters. As expected, serum FSH and LH showed a significant negative correlation with all the sperm parameters except semen volume (Table 4). With regard to semen hormones, semen PRL in the SFA abnormal group showed a significant negative correlation with the sperm motility, morphology and the sperm viability. Semen E2 showed a significant negative correlation only with sperm motility. No significant correlation was evident between semen FSH, LH and T and any of the sperm parameters (Table 4). 
Table 1. Mean semen variables of men with normal $(n=123)$ and abnormal $(n=260)$ semen

\begin{tabular}{lccc}
\hline Semen variable & $\begin{array}{c}\text { Men with } \\
\text { Normal SFA } \\
(\mathrm{n}=123)\end{array}$ & $\begin{array}{c}\text { Men with } \\
\text { Abnormal SFA } \\
(\mathrm{n}=260)\end{array}$ & P value \\
\hline Semen volume $(\mathrm{ml})$ & $3.3 \pm(1.1)$ & $2.7 \pm(1.4)$ & 0.001 \\
Concentration $\left(10^{6} / \mathrm{ml}\right)$ & $80.4 \pm(73.5)$ & $30.7 \pm(52.0)$ & 0.001 \\
Motility 'a'+'b' $(\%)$ & $60.8 \pm(7.3)$ & $33.8 \pm(19.3)$ & 0.001 \\
Normal morphology $(\%)$ & $57.3 \pm(10.5)$ & $44.9 \pm(21.3)$ & 0.002 \\
Viability $(\%)$ & $73.1 \pm(8.8)$ & $47.2 \pm(21.4)$ & 0.001 \\
\hline
\end{tabular}

SFA = seminal fluid analysis

$\mathrm{n}$ = number

Table 2. Mean serum and seminal plasma hormone concentrations of men with normal and abnormal semen

\begin{tabular}{|c|c|c|c|}
\hline \multicolumn{2}{|c|}{ Mean Hormone Value } & \multirow{2}{*}{$\begin{array}{c}\begin{array}{c}\text { Men with } \\
\text { Normal SFA } \\
(n=123)\end{array} \\
3.09 \pm 0.25 \\
1.18 \pm 0.24\end{array}$} & \multirow{2}{*}{$\begin{array}{c}\begin{array}{c}\text { Men with } \\
\text { Abnormal SFA } \\
(n=260)\end{array} \\
\begin{array}{c}6.04 \pm 0.39 t \\
1.49 \pm 0.15\end{array}\end{array}$} \\
\hline $\mathrm{FSH}(\mathrm{mIU} / \mathrm{ml})$ & $\begin{array}{l}\text {-Serum } \\
\text {-Seminal plasma }\end{array}$ & & \\
\hline $\mathrm{LH}(\mathrm{mIU} / \mathrm{ml})$ & $\begin{array}{l}\text {-Serum } \\
\text {-Seminal plasma }\end{array}$ & $\begin{array}{l}4.86 \pm 0.30 \\
1.52 \pm 0.09\end{array}$ & $\begin{array}{l}5.73 \pm 0.27 \\
2.02 \pm 0.27\end{array}$ \\
\hline PRL (mIU/ml) & $\begin{array}{l}\text {-Serum } \\
\text {-Seminal plasma }\end{array}$ & $\begin{array}{l}310.8 \pm 13.1 \\
455.4 \pm 78.5 \ddagger\end{array}$ & $\begin{array}{l}291.7 \pm 23.3 \\
776.5 \pm 69.1 \ddagger^{*}\end{array}$ \\
\hline $\mathrm{E} 2(\mathrm{pmol} / \mathrm{l})$ & $\begin{array}{l}\text {-Serum } \\
\text {-Seminal plasma }\end{array}$ & $\begin{array}{l}124.9 \pm 5.9 \\
309.8 \pm 10.2 \ddagger\end{array}$ & $\begin{array}{l}126.3 \pm 7.4 \\
340.1 \pm 14.1 \ddagger^{*}\end{array}$ \\
\hline $\mathrm{T}(\mathrm{nmol} / \mathrm{l})$ & $\begin{array}{l}\text {-Serum } \\
\text {-Seminal plasma }\end{array}$ & $\begin{array}{l}19.5 \pm 0.68 \\
2.97 \pm 0.43\end{array}$ & $\begin{aligned} 18.34 & \pm 0.54 \\
2.65 & \pm 0.16\end{aligned}$ \\
\hline $\begin{array}{l}\text { serum hormo } \\
\text { group } \\
\text { * } \begin{array}{l}\text { semen hormo } \\
\text { normal grouf }\end{array} \\
\ddagger \text { semen hormo } \\
n \quad=n \\
\text { SFA }=\text { s } \\
\text { FSH }=F \\
\text { E2 }=\mathrm{E} \\
\text { PRL }=\mathrm{P}\end{array}$ & $\begin{array}{l}\text { ne level in the SFA abnormal } \\
\text { ne level in the SFA abnormal } \\
\text { ne level is significantly higher } \\
\text { umber } \\
\text { minal fluid analysis } \\
\text { llicle Stimulating Hormone } \\
\text { stradiol } \\
\text { rolactin }\end{array}$ & $\begin{array}{l}\text { ip is significantly } \\
\text { ip is significantly }\end{array}$ & $\begin{array}{l}\text { than that of norma } \\
\text { than that of } \\
\text { evel }\end{array}$ \\
\hline
\end{tabular}


Table 3. Correlation (rvalues) of serum and seminal plasma hormone levels with semen variables in the semen normal group $(n=123)$

\begin{tabular}{lccccc}
\hline Hormone & Volume & Count & Motility & Morphology & Viability \\
\hline Serum FSH & -0.117 & -0.068 & 0.012 & 0.171 & 0.089 \\
Semen FSH & -0.059 & -0.024 & -0.009 & -0.173 & 0.16 \\
Serum LH & 0.035 & -0.119 & -0.104 & -0.054 & -0.083 \\
Semen LH & -0.083 & -0.063 & -0.01 & -0.001 & -0.107 \\
Serum PRL & 0.048 & -0.057 & 0.169 & -0.034 & 0.087 \\
Semen PRL & $0.281^{*}$ & -0.028 & $-0.204^{*}$ & -0.169 & 0.109 \\
Serum E2 & -0.059 & -0.022 & 0.076 & 0.089 & -0.108 \\
Semen E2 & 0.102 & -0.028 & -0.032 & 0.074 & 0.134 \\
Serum T & 0.069 & 0.055 & 0.012 & 0.182 & -0.013 \\
Semen T & 0.008 & -0.024 & 0.014 & 0.111 & 0.11 \\
\hline
\end{tabular}

* correlations are significant at $\mathrm{p}<0.01$

$\mathrm{FSH}=$ Follicle Stimulating Hormone

$\mathrm{LH}=$ Luteinizing Hormone

$\mathrm{E} 2=$ Estradiol

$\mathrm{T}=$ Testosterone

PRL = Prolactin

Table 4. Correlation ( $\mathrm{r}$ values) of serum and seminal plasma hormone levels with semen variables in the semen abnormal group $(n=260)$

\begin{tabular}{lccccl}
\hline Hormone & Volume & Count & Motility & Morphology & Viability \\
\hline Serum FSH & 0.06 & $-0.39^{* *}$ & $-0.213^{*}$ & $-0.416^{* *}$ & $-0.417^{* *}$ \\
Semen FSH & -0.11 & 0.182 & 0.006 & $-0.173^{*}$ & $-0.162^{*}$ \\
Serum LH & -0.032 & $-0.195 \ddagger$ & $-0.196 \ddagger$ & $-0.335^{* *}$ & $-0.338^{* *}$ \\
Semen LH & -0.087 & 0.03 & 0.01 & -0.18 & -0.16 \\
Serum PRL & 0.042 & -0.021 & -0.021 & -0.146 & -0.2 \\
Semen PRL & $0.215 \ddagger$ & -0.075 & $-0.398^{*}$ & $-0.322^{* *}$ & $-0.328^{* *}$ \\
Serum E2 & -0.043 & -0.072 & -0.058 & -0.081 & -0.12 \\
Semen E2 & -0.03 & -0.069 & $-0.231^{*}$ & -0.171 & $-0.198^{*}$ \\
Serum T & -0.011 & -0.021 & -0.033 & -0.15 & -0.164 \\
Semen T & -0.014 & -0.039 & 0.028 & -0.015 & -0.054 \\
\hline
\end{tabular}

$\ddagger$ correlations are significant at $p<0.05$

* correlations are significant at $p<0.01$

** correlations are significant at $p<0.001$

$\begin{array}{ll}\text { FSH }=\text { Follicle Stimulating Hormone } & T=\text { Testosterone } \\ \text { LH }=\text { Luteinizing Hormone } & \text { PRL }=\text { Prolactin } \\ \text { E2 }=\text { Estradiol } & \end{array}$




\section{Discussion}

This is the only study done in Sri Lanka to evaluate the status of the main reproductive hormones in blood and seminal plasma of men seeking infertility treatment. The Reproductive Biology Laboratory of the Department of Obstetrics and Gynaecology, Faculty of Medicine, University of Colombo is a tertiary care centre, which receives countrywide referrals. The hormone estimations were performed using an immunometric assay in a highly sensitive fully automated immuno-chemistry analyzer. As the equipment is used worldwide it is possible to compare the results of this study with those from other centres.

As in countries worldwide (10) this study carried out in Sri Lanka also illustrates an unacceptably high prevalence of male factor infertility. This high incidence of male infertility should be viewed in the context of a rising tide of male reproductive tract pathology during the past four or five decades. $(1,11)$. The end result of all pathologies of male reproductive tract manifests as deficiency in sperm production, transport or abnormalities in other sperm parameters. In order to address these changes in the male reproductive function, there is a clear need to acquire a deeper understanding of the cellular mechanisms involved in the genesis, differentiation, maturation, transport and function of human spermatozoa. This information will then provide the background to developing an understanding of the mechanisms underlying specific pathologies of the male reproductive tract and hence plan appropriate methods of treatment.

In keeping with results from studies worldwide this study showed that seminal plasma FSH, LH, and T levels were lower and PRL and E2 were higher than those in the serum $(6,7,12)$. Further, higher levels of seminal plasma PRL and E2 in men with abnormal semen than normozoospermic men found in this study are in agreement with the results reported by Sueldo (12). However, these results are in disagreement with those of Gonzales (7). Similarly, the finding of high seminal plasma E2 levels in men with abnormal semen parameters is in concordance with the findings of Bujan (6) and Luboshitzky (13) and are not in agreement with those of Gonzales. We cannot explain this discrepancy at present with the available data. However it is unlikely to be due to differences in ethnicity and geographical variation. It is also unlikely to be due to methodological sensitivities as most of the reported data were generated through highly sensitive immunometric assays, which are being used by researchers worldwide.

This study also correlates the seminal plasma endocrine levels with all sperm parameters. Most of the reported studies worldwide are focused only on one or two sperm parameters. Seminal plasma PRL showed a negative correlation with sperm motility, viability and morphology. The linear correlation analysis performed evaluates the relationship between five semen reproductive hormones, and the sperm parameters showed the strongest negative association with sperm motility. There is no clear explanation as to why higher levels of these hormones are found in infertile men. The mechanism by which the semen hormones bring about negative effects on sperm will also affect their fertilization ability. High levels of semen hormones could occur due to dysfunction or impairment of the fluid reabsorption in the epididymis. Malabsorption may result in high levels of hormones in the seminal plasma, the high concentrations of which would be detrimental to spermatozoa. High levels of 
E2 are shown to have deleterious effects on spermatogenesis (14). Involvement of PRL during the process of spermatogenesis (14) indicates that these hormones in normal amounts are required for the male reproductive process, which would adversely affect when concentrations are low or high. The available evidence and the results of this study when taken together indicate that hormones in semen also occur in normal and pathological ranges. This is similar to the situation found in blood, but the normal limits are yet to be defined.

Currently there is no explanation as to how PRL affects the morphology of spermatozoa. However, it has to influence this process at testicular level. The mechanism by which PRL affects sperm motility may be via receptors or by any physical perturbation of the membrane. This however is yet to be clarified. A study has already been started to find the in-vitro effects of PRL on the sperm motility.

To our knowledge, a relationship between seminal PRL and sperm morphology and viability has not been reported earlier. The demonstration of a significant negative effect of PRL and E2 on sperm motility, morphology and viability in this study provides a useful marker in the diagnosis and management of male infertility due to deficiencies in these sperm parameters. The benefit of separating spermatozoa from seminal plasma with high PRL has already been reported by the same authors (15). Evaluation of seminal plasma in general and PRL in particular could be recommended as requirements to select cases for sperm separation for intra uterine insemination.

\section{Acknowledgements}

Authors wish to thank Diagnostic Products Corporation (DPC), USA and their local agents, Lanka Medical Imports (Pvt)
Limited, Sri Lanaka, who donated all the hormone assay test kits to carry out this study.

\section{References}

1. Irvine S. The environment and male infertility: Is male reproductive health deteriorating? In: Puri CP, Van Look PFA. eds. Sexual and reproductive health - Recent advances, future directions. New Delhi: New Age International (P) Ltd., 2001: 281-302.

2. Sinclair S. Male infertility: Nutritional and Environmental Considerations. 2002 http://www.maleinfertility.html (accessed on 05.06.2005).

3. Comhaire F. Sophisticated sperm analysis ever required? In: Rafael $\mathrm{Z}$. B, Diedrich K, Dudenhausen J.W, Mettler L, Schneider H.P.G, Shoham Z, eds. Controversies in Obstetrics Gynaecology and infertility. Israel: Oren Publisher Ltd, 2003: 77-80.

4. Burkman L.J. The motility of spermatozoa before and after capacitation. In: Grudzinskas J. G, Yovich J. L eds. Gametes - The spermatozoon. Cambridge University Press, 1995: 175-191.

5. Hess R.A. Estrogen in the adult male reproductive tract: A review. Reproductive Biology and Endocrinology 2003; 1 : 52-81.

6. Bujan L., Mieusset R., Audra N., Lumbroso S., Sultan C. Increased estradiol level of the seminal plasma of the infertile men. Human Reproduction $1993 ; 8: 74-77$.

7. Gonzales G.F. Seminal plasma and its relationship to sperm motility in men. Fertility and Sterility 1989; 51: 498-503. 
8. Sheth A.R., Mugatwala P.P., Shah G.V., Rao S.S. Occurrence of prolactin in human semen. Fertility and Sterility 1975; 26: 905-907.

9. World Health Organization. Laboratory manual for the examination of human semen and sperm-cervical interaction. 4 th ed. Cambridge: Cambridge University Press, 1999.

10. Graner C. Infertility. In: Wasserheit T, Haaga J. eds. Reproductive Health in Developing countries. Washington: National Academy Press, 1997: 611628.

11. Carlson E., Giwercman A., Keiding N., Skakkbaeck N.E. Evidence of decreasing quality of semen during last 50 years. British Medical Journal 1992; 305: 609-613,.

12. Sueldo C.E., Berger T., Kletzky O., Marrs
RP. Seminal prolactin concentration and sperm reproductive capacity. Fertility and Sterility 1985; 43: 632-5.

13. Luboshitzky R., Kaplan-Zverling, Shen-Orr Z., Nave R., Herer P. Seminal plasma androgen/estrogen balance in infertile men. International Journal of Andrology 2002; 25: 345-351.

14. Turek PJ. Endocrine Evaluation: Hypothalamic-Pituitary-Gonadal (HPG) Axis and control of spermatogenesis. In: Lecture notes, Department of Urology, University of California, San Francisco. 1997: 1- 27.

15. Wijeratne S., Seneviratne H.R., Ratnasooriya W.D. Comparative evaluation of three techniques used in separation of motile spermatozoa from semen samples with elevated prolactin levels. Journal of Sri Lanka College of Obstetricians and Gynaecologists. 2004; 26: 27-32. 